\title{
Antioxidant Activity of Purslane (Portulaca oleracea L.) Leaf Extract on the Levels of Ovarian Oxidative Stress and Reproductive Hormone in Rattus norvegicus Exposed to Cigarette Smoke
}

\author{
Astika Gita Ningrum*(D), Endyka Erye Frety (D), Ivon Diah (D), Zidni Hasbuna Shabran (D), Rida Eka Setiani(D), Erni Rosita Dewi(D) \\ Midwifery Study Program, Faculty of Medicine, Universitas Airlangga, Surabaya, Indonesia
}

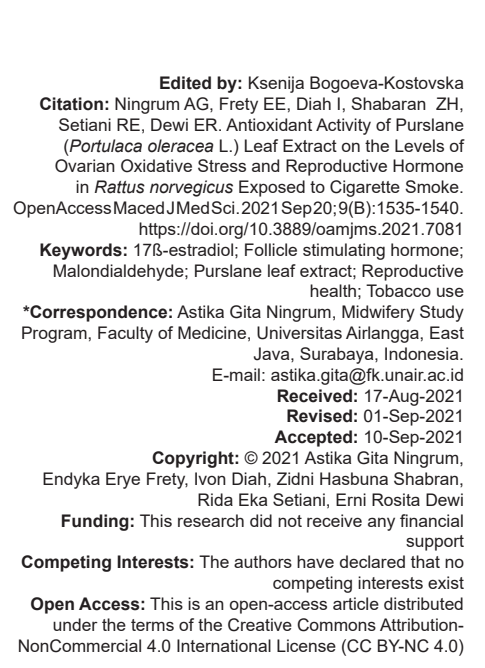

\section{Introduction}

Smoking habits harm the smoker and negatively affect those who inhale cigarette smoke (passive smoking). The global adult tobacco survey Indonesia in 2011 showed that the number of non-smokers (aged $\geq 15$ years) who became passive smokers in Indonesia showed a high number, namely, at work $(41.2 \%)$, at home $(75 \%)$, in government buildings $(55.7 \%)$, in health facilities $(16.5 \%)$, in places to eat/restaurants $(76 \%)$, in public transportation $(62 \%)$, in universities (49\%), in schools and educational facilities (31.9\%), and places of worship (12.7\%) [1].

Free radicals in cigarette smoke are exogenous free radicals that can cause oxidative stress that can cause damage to biological systems in the body [2]. Oxidative stress is the term used where there is an imbalance between reactive oxygen species (ROS) production and antioxidant defense [3]. Oxidative stress can occur due to reduced or absent antioxidants caused by mutations in enzymes that act as antioxidants such as Super Oxide Dismutase (SOD) or Glutathione
Peroxidase (GPX) or lack of dietary antioxidant. The increase in ROS also occurs due to excessive exposure to oxygen in the body and the presence of toxins whose metabolism produces ROS [4].

Cigarette smoke contains a lot of free radicals, which will increase the concentration of intracellular ROS. The impact and increase in ROS are oxidative stress that damages lipids, proteins, and DNA [5]. Oxidative stress caused by cigarette smoke can cause damage to the arcuate nucleus and ventromedial nucleus in the hypothalamus, resulting in a decrease in $\mathrm{GnRH}$ secretion, thus affecting the anterior pituitary in secreting hormones [6]. The previous research shows that nicotine that enters the body will act on nicotinic receptors in the hypothalamus, which will inhibit folliclestimulating hormone (FSH) secretion [7]. Antioxidant compounds interact by stabilizing free radicals to prevent oxidative stress in the body.

One of the plants that contain high antioxidants is purslane (Portulaca oleracea L.). It is a widely found plant in Indonesia because it is straightforward to grow in sandy or clay environments [8]. The antioxidant 
compounds contained in the purslane plant consist of gallotannins, omega-3 fatty acids, ascorbic acidtocopherols, kaempferol, quercetin, and apigenin [9]. Research on the effect of antioxidants on purslane that has been carried out in vivo shows that purslane extract influences oxidative stress levels in postmenopausal female mice, namely, reducing malondialdehyde (MDA) levels and increasing SOD levels in the ovaries and uterus [10]. Therefore, this study aims to measure ovarian MDA levels, FSH levels, and $17 \beta$-estradiol levels in the blood serum of females' white rats (Rattus Norvegicus) exposed to cigarette smoke and given purslane leaf extract.

\section{Materials and Methods}

The design of this study was an experimental approach randomized post-test only control group design. This research was conducted at the Pharmacology Laboratory, Faculty of Veterinary Medicine, UNAIR, Experimental Animal Laboratory, Faculty of Veterinary Medicine, UNAIR, Biochemistry Laboratory, Faculty of Medicine, UNAIR, and Biology Laboratory, Faculty of Science and Technology UNAIR from October-December 2020. The experimental protocol was approved by the Ethics Committee of the Faculty of Veterinary Medicine, Universitas Airlangga (UNAIR) with Ref. No: 2/KE/074/08/2020.

\section{Animal experimental}

The study used 12-week-old female Wistar strain $R$. norvegicus weighing about 200-250 g, kept in the Experimental Animal Laboratory, Faculty of Veterinary Medicine, Universitas Airlangga, Surabaya, East Java, Indonesia. The Wistar white rat was chosen as the research sample because the function, organ shape, biochemical, and biophysical processes are similar to humans, easy to maintain, and are relatively healthy animals, and are suitable for use in various types of research. Before the treatment, the rats underwent an acclimatization process for 1 week. Then they were divided into four treatment groups ( $n=6)$, namely, negative control without exposure to cigarette smoke and purslane leaf extract (K), cigarette group with cigarette smoke 1 stick/day administration without purslane leaf extract (P1), purslane group with purslane leaf extract $200 \mathrm{mg} / \mathrm{Kg} \mathrm{BW}$ without exposure to cigarette smoke (P2), and group the group with cigarette smoke 1 stick/day accompanied by purslane leaf extract $200 \mathrm{mg} / \mathrm{Kg} \mathrm{BW}$ administration (P3).

Before starting exposure to cigarette smoke and administering purslane leaf extract, a vaginal swab was performed to see the phase of the estrus cycle. Exposure started when the rat was in the proestrus phase. After exposure for 4 weeks, another vaginal swab was performed on day 28 to determine the proestrus phase. The dissected rats were in the proestrus phase. Determination of the proestrus phase before exposure and before dissection because in the proestrus phase, the influence of gonadotropin hormones in the form of FSH predominates in stimulating follicular development. Experimental animals were killed by anesthesia by injection intramuscular in the thigh using $1 \%$ ketamine to a dose of $0.2 \mathrm{~mL}$.

\section{Exposure to cigarette smoke}

Exposure to cigarette smoke is carried out in places far from humans and other animals to reduce the toxic risk of cigarette smoke. Exposure to cigarette smoke using a smoking pump was given as much as 1 stick/day (duration $\pm 4 \mathrm{~min}$ ) at noon (13.00) for 4 weeks after the subject completed the acclimatization and synchronization stages of the estrus cycle. After exposure to 1 cigarette for $4 \mathrm{~min}$, the experimental animals will be left in the cage for 30 min before being transferred. After that, the smoking area is cleaned by officers, where these officers must wear gloves, lab coats, and masks. In the control group or the smoke-free group, the experimental animals will still be placed in the smoking chamber according to the specified time but without being exposed to cigarette smoke. A smoking room or smoking chamber (a box made of fiberglass size $26 \times 12 \times 12$ ) is a box in which some bars form small boxes occupied by a test animal. The brand of cigarettes used is Gudang Garam Merah kretek cigarettes (tar content: 45.77 mg/stick; nicotine: $2.76 \mathrm{mg} / \mathrm{stick}$ ). After each subsequent exposure, the box is always cleaned first of the remaining cigarette smoke from the previous treatment.

\section{Leaf purslane extraction procedure}

Purslane leaf extract is made from purslane leaves selected, washed thoroughly, and then dried by drying in the sun and covered with a black cloth. After getting the simplicia preparation, it was then blended until smooth and then entered the maceration process. The maceration process starts from weighing the purslane powder and then putting it into a jar, pouring boiling distilled water into the mortar, adding $\mathrm{CMCNa}$ $1 \%$ of the weight of the purslane leaf extract to the mortar, and stirring slowly until dissolved. Add purslane leaf extract to the CMCNa solution that has been mixed with distilled water, and then stir until homogeneous.

\section{administration \\ Procedure for leaf extracts dosage}

Purslane administration of purslane leaf extracts using gavage method to experimental animals for 4 weeks after acclimatization and synchronization of the estrus cycle. Purslane leaf extract, dissolved with $1 \mathrm{ml}$ of $0.9 \% \mathrm{NaCl}$, is carried out in the morning before feeding. The purslane leaf extract is inserted into a $3 \mathrm{ml}$ 
syringe that has been fitted with a probe. Then, the probe tip is inserted orally through the palate into the pharynx and then into the mouth. Wistar strain white rat esophagus. Then, push the purslane leaf extract until it reaches the stomach. In the control group or the group without purslane leaf extract, experimental animals were still given sonde treatment containing $1 \mathrm{ml}$ of purslane leaf extract solvent, namely, $\mathrm{NaCl} 0.9 \%$. The sonde procedure using the gavage method is carried out by trained and competent laboratory personnel.

\section{Sampling}

Sampling was done after 4 weeks of treatment. Female Wistar white rats were smeared vaginally to determine the proestrus phase after surgery. Furthermore, blood is taken intracardially through the right ventricle of the heart; approximately $3 \mathrm{ml}$ of blood is taken through an injection syringe, and then put into a test tube without anticoagulant, which is then closed with a rubber stopper. Next, the left ovary was removed and put into a $10 \%$ formalin buffer solution.

Measurement of FSH levels and $17 \beta$-estradiol levels using the method Enzyme-Linked Immunosorbent Assay (ELISA). The work steps are adjusted to the guidelines listed in the Rat FSH ELISA antibody kit and the antibody rat $17 \beta$-estradiol ELISA kit with the brand BT-laboratory E1393Ra made in China. Meanwhile, the measurement of Ovarian MDA levels using the spectrophotometric method. The working steps were adjusted according to the guidelines listed in the BIOXYTECH MDA-586TM kit, Catalog Number 21044 Spectrophotometric Assay for MDA Antibody Rat.

\section{Statistical analysis}

Differences in MDA, FSH, and 17 -estradiol levels in the control and cigarette smoke groups were tested by independent-t-test. The difference in the effect of the intervention on the four groups was tested using a one-way analysis of variance (ANOVA) test for normally distributed data and followed by a further least significant difference (LSD) test to determine which groups were different. Data that were not normally distributed were subjected to Kruskal-Wallis nonparametric tests, followed by the Mann-Whitney test using Statistical Package for the Social Sciences (SPSS) version 20.0 (SPSS Inc, Body Mass Index). The confidence interval was determined at $95 \%$ and was declared significant if $p<0.05$.

\section{Results}

Effect of exposure to cigarette smoke on the levels of MDA and reproductive hormones in white rats ( $R$. norvegicus female).
The results of the test of differences in exposure to cigarette smoke on FSH levels and folliculogenesis were carried out by comparing the negative control group $(\mathrm{K})$ with the cigarette exposed female white rats (P1) showed a significant increase in MDA levels and but no significant changes in FSH and $17 \beta$ estradiol levels as shown in Table 1.

Table 1: Effect of exposure to cigarette smoke on MDA levels and reproductive hormones in white rats ( $R$. norvegicus female)

\begin{tabular}{llll}
\hline Variable & K Mean \pm Standard deviation & P1 Mean \pm standard deviation & p-value \\
\hline MDA level & $7.03 \pm 1.31$ & $13.83 \pm 1.6$ & 0.000 \\
FSH level & $4.58 \pm 0.73$ & $5.27 \pm 3.74$ & 0.667 \\
$17 \beta$ Estradiol & $27.19 \pm 4.62$ & $27.59 \pm 7.08$ & 0.910 \\
\hline If the $p \leq 0.05$ means that there is a significant difference and if the $P>0.05$ means that there is no a significant \\
difference, MDA: Malondialdehyde, $F S H:$ Follicle stimulation hormone.
\end{tabular}
difference, MDA: Malondialdehyde, FSH: Follicle stimulation hormone.

Table 1, based on the results of the independent sample t-test and independent sample t-test, shows that there is a significant difference $(p=0.000)$ in the mean MDA levels between the control group (K) $(7.03 \pm 3.8$ $\mathrm{nmol} / \mathrm{mg}$ ) and the cigarette smoke group (P1) (13.83M \pm $4.36 \mathrm{nmol} / \mathrm{mg}$ ). This means that rats exposed to cigarette smoke showed the higher MDA levels when compared to healthy rats. However, no significant differences in FSH $(p=0667)$ and levels $17 \beta$-Estradiol $(p=0.910)$.

The effect of purslane leaf extract on MDA levels in white rats ( $R$. norvegicus female) is exposed to cigarette smoke.

Based on the results of the test one-way ANOVA on MDA level data, it was obtained that there was a significant difference in the mean MDA levels of the four groups of observational samples. This was indicated by $p=$ 0.000. Furthermore, the multiple comparison test (Multiple Comparison) with the test LSD is presented in Table 2.

Table 2: Comparison of the effect of purslane leaf extract on MDA levels (nmol/mg)

\begin{tabular}{llll}
\hline Observation group & $\mathrm{n}$ & Mean \pm standard deviation & p-value \\
\hline K (negative control) & 6 & $7.03 \pm 1.31^{\mathrm{a}}$ & 0.002 \\
$\mathrm{P} 1$ (cigarette smoke) & 6 & $13.83 \pm 1.6^{\mathrm{b}}$ & \\
$\mathrm{P} 2$ (purslane leaf extract) & 6 & $7.447 \pm 1.98^{\mathrm{a}}$ & \\
P3 (cigarette smoke + & 6 & $9.167 \pm 4.79^{\mathrm{a}}$ & \\
purslane $200 \mathrm{mg} / \mathrm{kgBB} /$ day) & & & \\
\hline
\end{tabular}

The results of the LSD test are shown in the mean \pm SD column if it contains letters that are different, it means that there is a significant difference $(p \leq 0.05)$ and if containing the same letters means that there is no significant difference $(p>0.05)$, MDA: Malondialdehyde, LSD: Least significant difference.

In Table 2, based on the results of the multiple comparison test with the test, LSD shows that there is a significant difference in the mean MDA levels between the cigarette smoke group (rats exposed to cigarette smoke) $(13.830 \pm 4.35 \mathrm{nmol} / \mathrm{mg})$ and the treatment group exposed to cigarette smoke and purslane leaf extract with a dose of $200 \mathrm{mg} / \mathrm{kg} \mathrm{BW} /$ day $(9.167 \pm 12.612 \mathrm{nmol} / \mathrm{mg})$. This means that the treatment of purslane leaf extract at a dose of $200 \mathrm{mg} / \mathrm{kg} \mathrm{BW/day} \mathrm{in} \mathrm{female} \mathrm{rats} \mathrm{exposed}$ to cigarette smoke can reduce MDA levels.

The effect of purslane leaf extract on $\mathrm{FSH}$ levels in white rats ( $R$. norvegicus female) exposed to cigarette smoke.

Based on the results of the Kruskal-Wallis on $\mathrm{FSH}$ level data, there was no significant difference in 
the mean FSH levels of the four groups of observational samples; this was indicated by the value $p=0.315$ shown in the presented value in Table 3.

Table 3: Comparison of the effect of purslane leaf extract on FSH levels ((mIU/ml)

\begin{tabular}{llll}
\hline Observation group & $\mathrm{n}$ & Mean \pm standard deviation & $\mathrm{p}$-value \\
\hline K (negative control) & 6 & $4.5750 \pm 0.73$ & 0.315 \\
P1 (cigarette smoke) & 6 & $5.2650 \pm 3.74$ & \\
P2 (purslane leaf extract) & 6 & $3.3350 \pm 1.65$ & \\
P3 (cigarette smoke + & 6 & $4.8183 \pm 4.84$ & \\
purslane 200mg/kgBB/day) & & & \\
\hline If the $p \leq 0.05$ means that there is a significant difference and if the $p>0.05$ means that there is no a
\end{tabular}

If the $p \leq 0.05$ means that there is a significant differe

Although there was no significant difference in the effect of purslane leaf extract on the FSH levels of female white rats given cigarette smoke, Table 3 shows an increase in $\mathrm{FSH}$ levels in the P1 group (rats exposed to cigarette smoke) compared to the control group (healthy rat). Moreover, there was a decrease in the mean in Group P3 (rats exposed to cigarette smoke and given purslane leaf extract) close to FSH levels in healthy rats compared to Group P1 (rats exposed only to cigarette smoke).

Effect of the extract of leaves of purslane on levels of $17 \beta$-estradiol in rats (R. norvegicus) females exposed to cigarette smoke

Based on the test results Kruskal on the data content of the $17 \beta$-estradiol result, there is no significant difference in the mean levels of $17 \beta$-estradiol between four groups of sample observations, as shown by $p=0.081$, as presented in Table 4 .

Table 4: Comparison of the effect of purslane leaf extract on levels of $17 \beta$-Estradiol (ng/L)

\begin{tabular}{|c|c|c|c|}
\hline Observation group & $\mathrm{n}$ & Mean \pm standard deviation & $\mathrm{p}$-value \\
\hline K (negative control) & 6 & $27.1917 \pm 4.62$ & 0.081 \\
\hline P1 (cigarette smoke) & 6 & $27.5917 \pm 7.09$ & \\
\hline P2 (purslane extract leaves) & 6 & $17.65 \pm 6.55$ & \\
\hline P3 (cigarette smoke + & 6 & $22.53 \pm 6.02$ & \\
\hline
\end{tabular}

Although there was no significant difference in the effect of purslane leaf extract on the levels of $17 \beta$-estradiol in female white rats given cigarette smoke, Table 4 shows a decrease in the mean levels of $17 \beta$-estradiol in the P3 group (rats exposed to cigarette smoke and given purslane leaf extract) close to FSH levels in healthy rats compared to the P1 group (rats exposed only to cigarette smoke). However, in group P2 (purslane leaf extract administration), data on a decrease in $17 \beta$-estradiol levels was found, much lower than $17 \beta$-estradiol levels in the healthy rat (control group).

\section{Discussion}

The study found that cigarette smoke in female white rats caused a significant increase in MDA levels compared to the $\mathrm{K}$ group (negative control). Cigarette smoke is one of the exogenous free radicals that can enter the blood circulation to interfere with all cells and tissues in the body [11]. The human body physiologically produces antioxidants to counteract the reactivity of free radicals. These antioxidants capture free radicals and prevent the amplification of their reactivity by cutting the chain reaction of free radicals with cellular components, so these antioxidants are also called free radical scavengers [12]. If the number of free radicals exceeds the number of antioxidants in the body, free radicals will increase ROS in the blood. If this condition continues without any resistance from the body, oxidative stress will occur [13]. This is in line with $\mathrm{Hu}$ et al. (2014), which states an increase in lipid peroxidation, namely, MDA levels, and a decrease in SOD in the plasma of rats exposed to cigarette smoke in moderate and heavy doses [14]. Many methods for assessing oxidative stress are based on measuring the concentration of relatively stable peroxidation products. End-products of lipid peroxidation, oxidized proteins, and fragmented DNA or DNA oxidation biomarkers fall into three categories. The short life span of the assayed products limits the use of the majority of the indices.

Moreover, each available assay suffers from potential artifacts related to sampling, storage, and problems caused by the complexity of biological systems. Despite these issues, the determination of MDA and isoprostane concentrations is the most widely used indices for assessing oxidative stress because it is simple and reproducible. MDA is primarily a metabolic byproduct of the oxidation of polyunsaturated fatty acids with three or more double bonds. MDA would be expected to rise in the presence of increased oxidative stress [15]. Meanwhile, the impact of cigarette smoke on the levels of the hormones $\mathrm{FSH}$ and $17 \beta$-estradiol showed insignificant changes but tended to increase slightly. Due to increased oxidative stress, lipid peroxides occur, which can cause damage to the arcuate nucleus and ventromedial nucleus in the hypothalamus, resulting in impaired synthesis, and secretion of hypothalamic $\mathrm{GnRH}$. This failure will cause the pituitary to fail to synthesize and secrete $\mathrm{FSH}$ and $\mathrm{LH}$, so that it also affects the production of the hormone estrogen [16]. Owj et al. (2007) also showed the same result, namely, an insignificant increase in $\mathrm{FSH}$ levels in women who became passive smokers [17].

The results showed that MDA levels in rats exposed to cigarette smoke and given purslane leaf extract were significantly lower than in rats exposed only to cigarette smoke, but not lower than in the negative control group or purslane leaf extract alone. The findings of this study are consistent with other in vivo studies on the effect of antioxidants on purslane, which show that purslane extract affects the level of oxidative stress in postmenopausal female mice, namely, lowering MDA levels increasing SOD levels in the ovaries and uterus [10]. Purslane (P. oleracea L.) is a 
common plant in Indonesia due to its ease of cultivation in sandy or clay soils [8]. Purslane is essentially a weed in lawns and plantation crops. Purslane herb contains phytochemicals such as sterols, carotenoids, flavonoids, polyphenolic acids, polysaccharides, and reducing agents. According to phytochemical analysis, purslane extracted with ethanol is known to contain phenolic and flavonoid components [18]. Purslane contains antioxidant compounds such as gallotannins, omega-3 fatty acids, ascorbic acids, -tocopherols, kaempferol, quercetin, and apigenin [9]. According to research by Andarwulan et al. (2010), the flavonoid component in purslane ethanol extract has antioxidant activity [18]. According to Lolo et al. (2017), the phenolic components of purslane have antioxidant activity [19]. Lim et al. (2014) investigated the antioxidant activity of the entire purslane plant [20]. Each purslane plant organ contains a different number of phenolic compounds and flavonoids [9]. Purslane has antioxidant activity ranging from $10.21 \%$ to $70.97 \%$, with antioxidant compounds found in the form of polyphenols (8.43-13.90 $\mathrm{mg} \mathrm{GAE} / \mathrm{g}$ ) and flavonoids (22.14-64.33 mg/g) [21].

Purslane leaf extract activity in the $\mathrm{P} 2$ and $\mathrm{P} 3$ rat groups showed lower FSH and $17 \beta$-Estradiol compared to the $\mathrm{K}$ and $\mathrm{P} 1$ rat groups, but the difference was not statistically significant. This is consistent with Okafor's (2021) study on the hormonal effects of purslane extract on normal female rats ( $\mathrm{LH}, \mathrm{FSH}, \mathrm{PG}$, and E2), which found no significant differences when compared to the control group [22]. Hosseini et al. (2016) reported the same findings regarding the effect of purslane extract on levels of estrogen, progesterone, prolactin, and gonadotropins in adult female rats, namely, that there was no significant difference [23]. The anterior pituitary gland secretes $\mathrm{FSH}$, which is required for follicular growth until the antrum develops. During the 1 week of the menstrual cycle, FSH secretion is at its peak and most critical. FSH stimulates the ovaries' secretion of estrogen and progesterone, as well as granulose cell proliferation and $\mathrm{LH}$ receptor expression in granulosa cells [24]. The reduction in FSH concentrations suggests that this extract of Portulaca oleracea leaf may affect the anterior pituitary, the site of gonadotropin synthesis and secretion. According to these findings, the lower serum FSH levels caused by the extracts can inhibit folliculogenesis and follicular maturation, both of which are associated with the proestrus phase of the estrus cycle [25]. During the proestrus phase, the decrease in $\mathrm{FSH}$ concentration was accompanied by a decrease in $17 \beta$-Estradiol levels; however, the decrease in $17 \beta$-Estradiol concentration was not significant. There is usually an increase in the concentration of FSH during the growth and maturation of follicles during proestrus, which triggers the development and maturation of follicles in animals. These follicular theca cells produce androgens, converted to estrogen by the aromatase enzyme in the granulosa cells [26].

\section{Conclusion}

Based on studies on experimental animals, it was concluded that there were no significant changes in $\mathrm{FSH}$ and $17 ß$-estradiol. Therefore, it is necessary to perform further research on the antioxidant activity of purslane leaf extract on the female reproductive organs using experimental animal samples with several doses used to observe which doses are effectively counteracting free radicals.

\section{References}

1. GATS. Global Adults Tobacco Survey Indonesia Report 2011 New Delhi: World Health Organization Regional Office for South-East Asia; 2011

2. Agarwal A, Mellado AA, Premkumar, BJ, Sharma A, Sajal G. The effects of oxidative stress on female reproduction: A review. Reprod Biol Endocrinol. 2012;10:49.

3. Tandon VM, Gupta BM, Tandon R. Free radicals, reactive oxygen species. J K Practitioner 2005;12(3):143-8

4. Halliwell B, Gutteridge JM. Free Radicals is Biology and Medicine. $4^{\text {th }}$ ed. Oxford: Oxford University Press Inc.; 2007.

5. Uračková Z. Some current insights into oxidative stress. Physiol Res 2010;59(4):459-69. https://doi.org/10.33549/ physiolres.931844

PMid:19929132

6. Giovambattista A, Suescun MO, Nessralla CC, França LR, Spinedi E, Calandra RS. Modulatory effects of leptin on leydig cell function of normal and hyperleptinemic rats. Neuroendocrinology. 2003;78(5):270-9. https://doi. org/10.1159/000074448

7. Oyeyipo IP, Raji Y, Bolarinwa AF. Nicotine alters male reproductive hormones in male albino rats: The role of cessation. J Hum Reprod Sci. 2013;6(1):40-4. https://doi. org/10.4103/0974-1208.112380

PMid:23869150

8. Dalimartha S. Atlas of Indonesian Medicinal Plants. Vol. 5. Jakarta: Mother's Library; 2006.

9. Zhou $\mathrm{YX}$, Xin HL, Rahman K, Wang SJ, Peng C, Zhang $\mathrm{H}$. Portulaca oleracea L.: A review of phytochemistry and pharmacological effects. BioMed Res Int 2015;2015:925631. https://doi.org/10.1155/2015/925631 PMid:25692148

10. Ahangarpour A, Lamoochi Z, Moghaddam HF, Mansouri SM. Effects of Portulaca oleracea ethanolic extract on reproductive system of aging female mice. Int $\mathrm{J}$ Biomed Reprod. 2016;14(3):205-12.

PMid:27294220

11. Zjačić-Rotkvić V, Kavur L, Cigrovski-Berković M. Hormones and aging. Acta Clin Croat. 2010;49(4):549-54.

PMid:21830471

12. Winarsi H. Natural Antioxidants and Free Radicals: Potential and Applications in Health. Yogyakarta: Canisius Publisher; 2007.

13. Devasagayam TP, Tilak JC, Boloor KK, Sane KS, Ghaskadbi SS Lele RD. Free radicals and antioxidants in human health: Current status and future prospects. J Assoc Physicians India. 
2004;52:794-804.

PMid:15909857

14. Hu JP, Zhao XP, Ma XZ, Wang Y, Zheng LJ. Effects of cigarette smoke on aerobic capacity and serum MDA content and SOD activity of animal. Int J Clin Exp Med. 2014;7(11):4461-65.

PMid:25550969

15. Kelly G. The interaction of cigarette smoking and antioxidants. Part I: Diet an carotenoids. Altern Med Rev 2002;7:370-88. PMid:12410622

16. Sadeu JC, Foster WG. Cigarette smoke condensate exposure delays follicular development and function in a stage dependent manner. Fertil Steril. 2011;95(7):2410-7. https://doi. org/10.1016/j.fertnstert.2011.03.072

17. Owj M, Mohseni M, Amirchaghmaghi E, Sadeghi M, Eshrati B, Shabani $F$. The relationship between passive smoking and ovarian response outcome in ART cycles. Iran J Reprod Med. 1996;5(4):195-8.

18. Andarwulan N, Batari R, Sandrasari DA, Boilling B, Wijaya $H$. Flavonoid content and antioxidant activity of vegetables from Indonesia. Food Chem. 2010;121(4):1231-5.

19. Lolo WA, Sudewi S, Edy HJ. Determination of the value of the sun protecting factor (SPF) of purslane herb (Portulaca oleracea L.). J Pharm Sci Clin Res. 2017;2(1):1-5.

20. Lim CK, Tiong WN, Loo JL. Antioxidant activity and total phenolic content of different varieties of Portulaca grandiflora. IJPP. Indian J Pract Pediatr. 2014;4(1):2277-928.

21. Disti S. Chemical Characteristics and Bioactive Components of Extract Powder from Various Parts of Purslane Plant (Portulaca oleracea L.), Diploma Thesis. Indonesia: Andalas University; 2018.

22. Okafor IA, Nnamah US, Nnaka J. The fertility assessment of normal cyclic Wistar rats following the administration of methanolic extract of Portulaca oleracea: An experimental study. Middle East Fertil Soc J. 2021;26:5. https://doi.org/10.1186/ s43043-020-00048-x

23. Hosseini E, Frozanfar M, Payehdar A. The effect of hydroalcoholic extract of purslane on serum concentration of estrogen, progesterone, prolactin and gonadotropins in mature female rats. J Shahrekord Univ Med Sci. 2021;15(5):12-21.

24. Grestein B, Wood Diana F. Endocrine System. Jakarta: Erlangga; 2010.

25. Obinna VC, Kagbo HD, Agu GO. Lipophilic and hydrophilic leaf extracts of Portulaca oleracea (Purslane) disrupts female sex hormones in albino rats (Rattus norvegicus). J Tradit Complement Med. 2021;11(2):82-9.

26. Sejian V, Meenambigai TV, Chandirasegaram M, Naqvi SM. Reproductive technology in farm animals: New facets and findings: A review. J Biol Sci. 2010;10(7):68. 